\title{
Introduction for Caribbean Pelau
}

\author{
Eugene Williams \\ Professor Emeritus, Edna Manley College \\ Kingston, Jamaica
}

Ever since Anglo-Caribbean societies began their process of anti-colonial resistance in the 1930's and continued through the postcolonial reconstructive decades of independence in the 1960's and 70's, the arts - both of the traditional and the fine variety, have been championed with varying degrees of institutional support and success as a vehicle for humanistic education and aesthetic enrichment. Cultural artefacts and the arts have served as tools for excavating cultural memory as well as expressive forms of validation and celebration of identity, nationhood and self-determination, in schools and the societies at large.

However, this trajectory of nation building and self-empowerment, particularly of the marginalized, is now in crises. Internal failures of leadership and an apparent detour from a people and community centred approach to development are among the causal factors identified. Perhaps the most important underlying factor though has been the derailment by the pervasive neo-liberal globalizing model of development which privileges a dominant hegemonic way of being, seeing and doing. In the intractable march of this model, art making appears to be primarily conceived to be on an assembly line of the cultural industry, bound for the market place.

Fortunately, in spite of the disappointing pace and dubious sustainability of what has been achieved over the last four decades, there has been a great deal of transformation in the cultural consciousness of the Caribbean people and in institutional building in 'arts education' across the region. This has been the case both in the formal school system, and the informal laboratories of facilitation. These developments, as this edition of the journal will show, has undoubtedly planted seeds for transnational and diasporic collaborations and dialogue.

The papers in this edition have responded to a call for Caribbean voices which throw focus on arts education in the region by exploring the importance of the arts and culture in various aspects of education and social development. The concept of Arts Education is therefore not limited here to the formal school setting. The perspective is expansive - seeking to address a plurality of creative strategies employed by teachers/artists/researchers who have been engaged in the liberatory postcolonial project of opening doorways through their art, critical inquiry, creative pedagogy and facilitation of humanistic and aesthetic development. What is therefore served up here is a savory Caribbean admixture - A Pelau.

The menu of offerings aptly begins in the aforesaid decolonizing period of the 1930's with Professor Edward Baugh's eloquent memorializing of Edna Manley's seminal inspiration and encouragement of modern Jamaican literature. Drawing on interviews with the leading writers of the period all well as relevant archival material, Baugh's article celebrates Edna Manley's pivotal and vigorous intervention in the creation of a 'generative milieu of artistic, intellectual and social consciousness.' Her home in Drumblair in Kingston was the legendary 'nerve centre' for this creative offensive with early Jamaican artists and writers. The article also 
provides an interesting peek into Manley's personality as a passionately committed facilitator of the conception and publication of "new" Jamaican literature in that transformative period of the nation's development.

In Oneika Russell's insightful Notes on Paradise, she reminds us that the notion of the Caribbean and other similar tourist destinations being regarded as an exotic tropical paradise is a historical construction from a body of ideas conjured in the desire of pleasure-seeking visitors and potential visitors from the Western centres of power. She argues that on the other side of this encounter are the various operational hosts within the paradisiac enclaves of those destinations who perform conspiratorial and paradoxical roles in a market-driven exchange in which they too like space and place, become consumable commodities detached from the total reality of their lives and societies. Her discussion emerges out of her personal notes about encounters with individuals who have not visited Jamaica and her reflections as a visual artist on the colonial western fascination, particularly with her homeland of Jamaica. In this regard, her referencing of the exotic opus of Paul Gauguin who retreated from his stresses in the French metropolis to colonial Martinique and then to Tahiti, invokes the controversial critique of this period of his work as exoticism and objectification of Polynesian culture. There are several other interesting features of the article including Russell's critique of the branding campaigns of national Tourist Boards which project seductively 'bare and pristine landscapes' awaiting the footprints of the visitor - clearly pointing to a perpetuation of the narrative of the colonizing adventurer.

Theatre artist and teacher Dr. Jean Small shares her experience as teacher-director, adapting and staging two Francophone folktales with a group of tertiary students. This project was done for the purpose of teaching primarily the French language, as well as exposing students to theatre skills and social codes of behavior in the African tradition. Through this particular methodology the objective was 'to provide the students with an intimate experience of owning the text through performance.' The article highlights the virtues of this body-based theatre pedagogy which employs the kinesthetic and emotional intelligences. Dr. Small points out that this along with repetition of rehearsals allowed the students to perfect pronunciations, increase vocabulary and discuss literary themes in the material. She also assures that given the collective process of drama and the added benefits of the total theatre approach which was employed, students had a rewarding cooperative, aesthetic and cultural education.

Modernity and the age of globalizing technology are often blamed for the disappearance and neglect of traditional cultural forms of the Caribbean's intangible cultural heritage. In her essay, Glenda-Rose Nassoma Layne makes a strong case for the preservation of the cultural forms of the oral tradition of the region and their utilization, through process theatre, as a pedagogical tool for teaching social values and cultural heritage, to students. The examples that are provided: proverbs, mythical characters and folk songs along with translations, interpretations and cultural functions, underscore the writer's point that the forms constitute a school of 'lived history' that was designed to prepare everyone through a participatory and entertaining process, to 'face life.' In The Bele Dance - The Tobago Story we are treated by Glenda-Rose Nassoma Layne to a delectable anthropological overview of Tobago's creolized Bele Dance complex. This includes its historical lineage, ritual functions, performative vocabulary, and cultural accoutrement, in the 'lived culture' of Tobago. She even makes reference to the corresponding variations and crosspollinations in some of the other islands of the eastern Caribbean.

Cultural and Pedagogical Inquiry, Fall 2019, 11(3), pp. 3-6

ISSN 1916-3460 @ 2019 University of Alberta

http://ejournals.library.ualberta.ca/index.php/cpi/index 
Meagan Sylvester's authoritative discussion from Tobago's sister island of Trinidad explains the lyrical content of contemporary Calypso and Soca as a manifestation of political resistance. Sylvester points out that this musical evolution was spawned in the lineage of political transformation of the Trinidad Carnival experience. She contextualizes her argument by pointing to the transplantation of the European and African heritages of carnival and masquerade into the contested space of anti-hegemonic plantation society. Sylvester reminds us that in this volatile arena the chief instrument of cultural certitude of the oppressed Africans - the drum, was banned thereby leading to creative improvisations that shaped the musical language of cultural resistance of the marginalized which transformed the European festival into a space of defiance of the status quo and official decorum.

Dr. Nicholeen DeGrasse-Johnson and Professor Christopher Walker provide us with illuminating insider perspectives on the cultural, pedagogical and professional significance of the intersections between the National Dance Theatre Company (NDTC) and Edna Manley College's School of Dance - two institutions which have been pivotal to the development of Jamaican dance theatre since national Independence. Through the authors' sharing of their lived dance experiences both as insiders of the company, as well as students and faculty of the school, we are introduced to some of the reciprocities of the two institutions and their active relations with kindred diasporic companies which informed the creation of the company's foundational repertoire of modern contemporary dance expressions that are rooted in the Africanist heritage of Jamaica and the Caribbean.

Weaving themes of ancestralization, cultural memory and identity out of the Caribbean experience have been the focus of many of our literary, performing and visual artists. In the creative strategies employed by poets Yasmin Glinton and Charlotte Henay, we are treated to a compelling poetic triptych which seeks to locate and cultivate the seeds and fruits of identity and becoming in the interstitial gaps of ancestral rupture and memory. Their collective space is a mourning ground/memorial for ancestral mothers - their quest a rite of passage. Two different voices excavating and constructing vivid utterances that sparkle with visual and aural resonance in the imaginary and on the page.

When imaginative and empathetic teachers engage students who have been victims of abuse and other kinds of psychological trauma through a pedagogy of conscientization (Friere) reflection and liberatory action, they can undoubtedly make a positive difference by becoming an effective counterbalance to oppressive homes or communities; they can construct a productive alternative to the demonizing and punitive legacies of the plantation, in many classrooms.

Dennis Conrad, Beulah Forteau-Jaikaransingh and Theresa Abodeeb-Gentile share their collaborative intervention in this regard through a reflective 'poetic inquiry.' Their 'rounding out' or stitching together of rounds of poetic recollections (teacher and student) seemingly unlocked subjectivities and dismantled walls of fear and antipathy, which testify to the transformative value of the arts in education for both teacher and student.

The cultivation of critical thinking in the primary and secondary school classroom is regarded universally as a primary objective in order to develop empowered, confident as well as socially aware human beings for a democratized society. Yet, there continues to be criticism of curricula at crucial junctures at this level of education that focus entirely on standardized tests for academic progression. This was the motivating context for a qualitative action research study in 
which some Standard Four students, at a primary school in rural Trinidad, were introduced to Design Thinking in a vacation camp by three instructors - Lesley-Ann Noel, Tsai Lu Liu and Traci Rose Rider. Their essay outlines how Design Thinking approaches, that are primarily used in the business world for product and systems development, can inform pedagogy and enable students to take control of their education. Curriculum designers in the region who are committed to real social transformation through education might find this offering worthy of exploration within the structured school system.

Alix Pierre shares an insightful perspective on cultural intersection of Jamaican visual arts and African diasporic 'arts building' in North America. He locates his take as a participant within the Miami-based Diaspora Vibe Cultural Arts Incubator (DVCAI) which has been promoting dialogue between artists of the global south through international cultural exchanges for the last 22 years. Drawing on Marcus Garvey's philosophy of Pan-Africanism and 'race pride' as well as the work of contemporary scholars engaged in black diasporic studies, he points to a common purpose of DVCAI's international cultural exchange and the groundedness of Jamaican contemporary arts and arts institutions. In this regard, he spotlights the work of two outstanding Jamaican artists: Nari Ward whose work deals with race, immigration, poverty and Caribbean Identity and Ebony Patterson, a graduate of the Edna Manley College of Visual and Performing Arts (EMCVPA), who moves between Jamaica and the US. Patterson's work invites a reimagining of contemporary issues of race, gender and social violence. Pivotal to the article's themes of transnational dialogue is the DVCAI 2018 visit to Jamaica which focused on spaces of exhibition, arts education and arts creation. Pierre ascribes a significant pedagogical function to the EMCVPA and the Sculpture Park at the University of Technology in Jamaica - the former providing formal undergraduate arts education that enriches the aesthetic sensibilities and cultural diversity of the Caribbean and the latter described as an 'open air museum' providing cultural education for the campus and the wider community. 